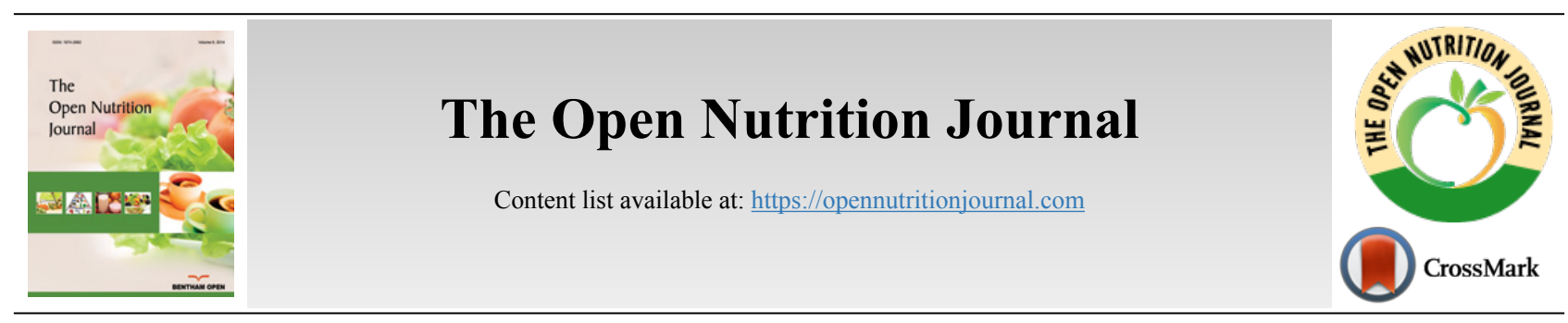

RESEARCH ARTICLE

\title{
A Questionnaire-based Assessment of Dietary Adherence and Identification of Barriers to Healthy Eating
}

\author{
Karen S. Bishop ${ }^{1,2, *}$, Weiming $\mathrm{Yi}^{2}$, Isabella Piper-Jarrett ${ }^{1}$ and Marcus A. Henning ${ }^{3}$ \\ ${ }^{\prime}$ Discipline of Nutrition and Dietetics, School of Medical Sciences, Faculty of Medical and Health Sciences, University of Auckland, Auckland, New \\ Zealand. \\ ${ }^{2}$ Auckland Cancer Society Research Centre, School of Medical Sciences, Faculty of Medical and Health Sciences, University of Auckland, Auckland, \\ New Zealand. \\ ${ }^{3}$ Centre for Medical and Health Sciences Education, School of Medical Sciences, Faculty of Medical and Health Sciences, University of Auckland, \\ Auckland, New Zealand.
}

\begin{abstract}
:
Background:

Adherence to a Mediterranean-style diet is associated with an extensive list of health benefits for people both with and without a disease.

Objective:

The objective of this study was to develop/modify a questionnaire to investigate the current adherence to a Mediterranean-style dietary eating pattern amongst the New Zealand male population, and to assess the association between perceived barriers to change and behaviours.

Methods:

The development of this questionnaire was based upon a modified 14-point validated Mediterranean diet adherence screener (PREDiMED) and included an additional section wherein we explored the reasons behind men's food choices and barriers to healthy eating. Questionnaires were analysed from 295 men. Descriptive analyses were used to determine major barriers to change.

Results:

The modification of the PREDiMED questionnaire resulted in a 23 question questionnaire encompassing adherence, demographics and barriers to change. We found that $90.8 \%$ of respondents had either low or intermediate adherence to a Mediterranean style diet. Significant associations also existed between adherence and smoking $(p=0.003)$, age $(p<0.01)$ and opinion of the importance of healthy eating $(p<0.01)$. We found participants felt the 'major' barrier to consume a healthy diet, to be a busy lifestyle, and the most common influencer of food choices was people.

Conclusion:

Through identifying how New Zealand men consume food and how they consider their barriers to change, we can better direct policy to aid changes in behaviour and integrate the Mediterranean style diet to complement the New Zealand food culture.
\end{abstract}

Keywords : Questionnaire, PREDiMED, Mediterranean style diet, Barriers to change, Busy lifestyle, Men, New Zealand.

\section{Article History} Received: February 02, 2019

Revised: March 30, 2019

Accepted: April 02, 2019

\section{INTRODUCTION}

Hippocrates theorised a connection between diet and health outcomes over 2400 years ago [1]. The full extent of this association has been investigated in depth as industrialisation, globalisation and technological development have altered the

* Address correspondence to this author at the Faculty of Medical and Health Sciences, University of Auckland, Private Bag 92019, Auckland, 1142, New Zealand; Tel: +6499234471; Email: k.bishop@auckland.ac.nz lifestyle of much of the global population. The Seven Countries Study, which commenced in 1950, was one of the first large scale longitudinal studies which identified a possible geographical link to health outcomes [2]. A key finding of this study was the reduced incidence of coronary heart disease in populations residing in countries surrounding the Mediterranean Sea such as Crete, Greece, Italy and Spain [2]. The positive health outcomes documented in these populations have 
been attributed to a lifestyle of adequate sunshine, physical activity and a diet which is high in locally produced fruits, vegetables, olive oil and grains.

The specific foods which are part of a Mediterranean style diet vary between countries surrounding the Mediterranean Sea, owing to the differences in food availability, climate and culture. In general, such a dietary pattern is high in olive oil, fruit and vegetables, pulses and legumes, oily fish and seafood, whole-grains, poultry, and low in red meat, dairy products and processed foods.

A number of systematic reviews and meta-analyses have been published on the physical and mental health benefits of following a Mediterranean style diet [3 - 5]. Adherence to a Mediterranean style diet has been shown to reduce blood pressure, inflammatory markers and oxidative stress $[6,7]$. In addition, high adherence to a Mediterranean style diet has been associated with decreased mortality rates, reduced risk of cardiovascular disease, reduced incidence of Parkinson's and Alzheimer's diseases and reduction in markers of oxidative stress $[8$ - 10]. These findings are primarily the result of epidemiological studies which have utilised variants of a Mediterranean diet adherence score as well as food frequency questionnaires. A Mediterranean diet adherence score can be calculated by analysing the intake of each of the main Mediterranean food groups, using a 9-point or 14-point system. A higher score represents higher adherence to a Mediterranean style diet [11].

The link between cancer progression and Mediterranean dietary patterns is a developing area of research, and there is favourable evidence suggesting that biochemical components of foods in a Mediterranean diet, such as omega 3 fatty acids from fish, and lycopene from tomatoes, can contribute to a reduction in markers associated with cancer risk [12].

In New Zealand (NZ) prostate cancer affects approximately 3000 men annually, with a $20 \%$ mortality rate [13, 14]. Risk of prostate cancer, to some extent, is modified by lifestyle. For this reason, we previously carried out a Mediterranean style dietary intervention in New Zealand men [15]. An association was identified between omega 3 polyunsaturated fatty acids and decreased DNA damage when a Mediterranean style dietary pattern was followed. It is relatively easy to design a dietary intervention; however, difficulties were experienced in following certain aspects of the diet. These data have prompted us to determine the current dietary patterns in men in NZ by carrying out a Dietary Adherence and identification of Barriers to change (DAB) Study.

\section{METHODS}

A questionnaire was administered to men residing in NZ between July and December 2017. The questionnaire was used to identify eating habits and perceived barriers to consuming a healthy diet.

\subsection{Study Participants}

To determine the number of questionnaire responses required, data was drawn from the NZ census [16]. The desired sample size of 385 was estimated using a $95 \%$ confidence interval and a margin of error of $5 \%$, with a total NZ male population of $1,323,960$ within the required age range. The authors distributed the questionnaires across the country via hardcopy and via an online Google form version. The online form did not allow for the submission of forms with missing data. Distribution took place via Facebook, estate agencies, Dunedin City Council, tertiary education institutions (in Auckland and Dunedin), the fire service and via word of mouth. A total of 296 responses were received and one response was excluded due to ineligible age. Inclusion criteria were as follows: male; aged between 25-80 years; residing in NZ.

\subsection{The Questionnaire}

The questionnaire was designed in three parts: parts one and two were used to investigate the current level of adherence to a Mediterranean style diet in NZ men in relation to demographics, and part three was used to identify barriers to change.

\subsection{Scoring System}

This questionnaire was used to measure the overall adherence to a Mediterranean style dietary eating pattern, as well as the consumption of individual food groups. A point was awarded if the consumption of the specific food group was above or below a cut-off value (Supplementary Table 1). The cut-off values were obtained from the questionnaires developed by Martinez-Gonzalez et al. [17] and further adapted by Schroder et al. [18]. These cut-off values were determined by a dose-response curve of food consumption in relation to cardiovascular disease risk [19].

An overall score out of 14 was calculated to determine the adherence to a Mediterranean style diet; higher adherence was linked with a higher number. Low, intermediate and high adherence scores were classified as $0-5,6-9$ and 11-14, respectively.

\subsection{Demographic Information}

Part two of the questionnaire consisted of six questions on age, ethnicity (in line with the NZ census classifications), income, education, smoking status and medical history of the participant.

\subsection{Behavioural Influences and Perceived Barriers to Healthy Eating}

Part three of the questionnaire was used to investigate the barriers to healthy eating and attitude towards current food choices. The purpose of this section was to gain insight into motivation behind specific eating habits and male attitudes towards implementing a healthier diet.

The first question; "Please select three of the following factors you believe are MAJOR barriers towards consuming a diet which is considered healthy", refers to a list of 21 possible perceived barriers to healthy eating. The list of perceived barriers to healthy eating was developed by a multi-disciplinary team as a result of a questionnaire-based study carried out in Spain [20].

The second question; "How important is healthy eating to you? And Why?" involved a selection of 1 (not important) to 6 
(very important) on a Likert scale. This was followed by an open question where the participant was asked to explain the reasoning behind their response to the previously closed question.

The final question: "What influences your current food choices?" allowed participants to present issues not previously captured by the closed questions.

\subsection{Statistical Analysis}

Correlations were conducted between the dependent variable of adherence and the independent variables age, income, each medical condition and opinion of importance of healthy eating. An Analysis of Variance (ANOVA) was used to determine relationships between the dependent variable of adherence and the independent variables ethnicity, education and smoking. Age was considered a covariate throughout the analyses. Part three was analysed descriptively. Each participant's response was categorised within each question and a natural point of inflection was found by qualitative assessment of diminishing returns. Categories with scores above this point were considered 'significant' factors and vice versa. The Likert Scale was also analysed descriptively by grouping the participants into three different motivation levels.

\section{RESULTS}

Eligible questionnaires were received from 295 eligible men, with a mean age of 47.7 years. The response rate could not be determined due to the nature of data collection. For example, it was not known how many potential participants read the advert on Facebook. In addition, a number of surveys were sent to a single person to distribute among their company or community. Whether they passed the information on was not known as responses were anonymous. Similarly, emails were sent out via a group email, but it is not known if the emails were read, or who they were read by. Participant characteristics are summarised in Table 1. 9.1\% of the study participants had a high level of adherence to a Mediterranean style diet, $66.1 \%$ had intermediate adherence and $24.7 \%$ had low adherence.

There is a statistically significant relationship between smoking status and adherence to a Mediterranean style diet with age as a covariate, $p=0.003$ (Table 2). Current smokers have lower adherence than past smokers than non-smokers. Age and opinion of importance of healthy eating were also both strongly correlated with adherence to a Mediterranean style diet (Table 3). The older the participant, the more adherent they were to the Mediterranean style diet and the more important the participant considered healthy eating, the higher their adherence.

Table 1. Demographic and health characteristics of respondents by adherence to a modified Mediterranean style diet.

\begin{tabular}{|c|c|c|c|c|}
\hline \multirow{2}{*}{$\begin{array}{c}- \\
\text { Characteristic }\end{array}$} & \multicolumn{4}{|c|}{ Adherence to a Mediterranean Style Diet } \\
\hline & Total & \begin{tabular}{|c|} 
Low \\
\end{tabular} & Intermediate & High \\
\hline $\mathrm{n}$ & 295 & 73 & 195 & 27 \\
\hline $\begin{array}{l}\text { Age in years } \\
\text { Mean (SD) } \\
\end{array}$ & $47.7(15.4)$ & $43.4(14.0)$ & $49.1(15.5)$ & $\begin{array}{c}49.6 \\
(15.9) \\
\end{array}$ \\
\hline $\begin{array}{c}\text { Income (NZ\$) } \\
\text { Median (SD) }\end{array}$ & $75,000(100,342)$ & $60,000(45,963)$ & $80,000(117,279)$ & $90,000(57,420)$ \\
\hline \multicolumn{5}{|l|}{ Ethnicity \% (n) } \\
\hline NZ European & $61.0(180)$ & $20.6(37)$ & $69.4(125)$ & $10.0(18)$ \\
\hline Maori/PI & $6.8(20)$ & $25.0(5)$ & $70.0(14)$ & $5.0(1)$ \\
\hline Asian & $17.3(51)$ & $31.4(16)$ & $58.8(30)$ & $9.8(5)$ \\
\hline Other European & $8.1(24)$ & $33.3(8)$ & $62.5(15)$ & $4.2(1)$ \\
\hline Other & $6.8(20)$ & $35.0(7)$ & $55.0(11)$ & $10.0(2)$ \\
\hline \multicolumn{5}{|c|}{ Highest level of education achieved \% (n) } \\
\hline Tertiary & $77.3(228)$ & $22.8(52)$ & $67.5(154)$ & $9.6(22)$ \\
\hline Other & $22.7(67)$ & $31.3(21)$ & $61.2(41)$ & $7.5(5)$ \\
\hline \multicolumn{5}{|c|}{ Smoking status \% (n) } \\
\hline Non-smoker & $72.5(214)$ & $20.6(44)$ & $70.1(150)$ & $9.3(20)$ \\
\hline Past-smoker & $22.0(65)$ & $29.2(19)$ & $63.1(41)$ & $7.7(5)$ \\
\hline Current smoker & $5.1(15)$ & $60.0(9)$ & $26.7(4)$ & $13.3(2)$ \\
\hline Non-response & $0.3(1)$ & $0.3(1)$ & $0.0(0)$ & $0.0(0)$ \\
\hline \multicolumn{5}{|c|}{ Medical conditions \% (n) } \\
\hline Any condition & $37.3(110)$ & $20.0(22)$ & $73.6(81)$ & $6.4(7)$ \\
\hline High cholesterol & $17.3(51)$ & $17.6(9)$ & $76.5(39)$ & $5.9(3)$ \\
\hline CVD & $6.8(20)$ & $15.0(3)$ & $85.0(17)$ & $0.0(0)$ \\
\hline HTN & $10.5(31)$ & $19.4(6)$ & $71.0(22)$ & $9.7(3)$ \\
\hline Cancer & $5.4(16)$ & $12.5(2)$ & $75.0(12)$ & $12.5(2)$ \\
\hline T2D & $3.7(11)$ & $18.2(2)$ & $63.6(7)$ & $18.2(2)$ \\
\hline Arthritis & $3.7(11)$ & $0.0(0)$ & $72.7(8)$ & $27.3(3)$ \\
\hline Lung disorder & $4.1(12)$ & $8.3(1)$ & $91.7(11)$ & $0.0(0)$ \\
\hline
\end{tabular}


(Table प) contd....

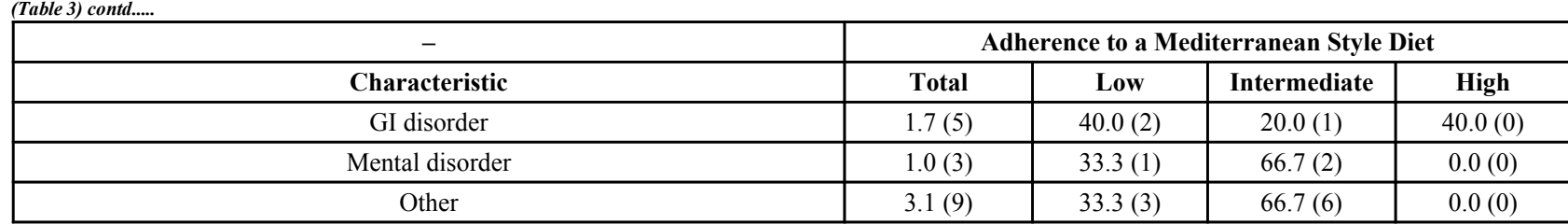

Low, intermediate and high adherence scores were classified as 0-5, 6-9 and 11-14 respectively. Abbreviations: $\mathrm{n}=$ number; NZ=New Zealand; PI=Pacific Islander; $\mathrm{CVD}=$ Cardiovascular Disease; HTN=Hypertension; T2D=Type 2 Diabetes Mellitus; GI=Gastro-Intestinal.

Table 2. A combined ANOVA table showing the relationship between the adherence score of NZ men to a modified Mediterranean diet and dependent variables, with age as a covariate.

\begin{tabular}{|c|c|c|}
\hline \multicolumn{2}{|c|}{ Dependent variables } & $\begin{array}{c}\text { Significance } \\
\text { (p-value, }(\text { F-value; } d \mathrm{df}))\end{array}$ \\
\hline Ethnicity & Mean (SD) & \multirow{6}{*}{$0.88(0.92 ; 4)$} \\
\hline NZ European & $7.02(1.88)$ & \\
\hline Maori/PI & $6.55(1.88)$ & \\
\hline Other & $6.50(2.37)$ & \\
\hline Asian & $6.37(2.23)$ & \\
\hline Other European & $6.42(2.06)$ & \\
\hline Education level & Mean (SD) & \multirow{3}{*}{$0.17(1.89 ; 1)$} \\
\hline Tertiary & $6.83(2.03)$ & \\
\hline Non-tertiary & $6.66(1.91)$ & \\
\hline Smoking status & Mean (SD) & \multirow{4}{*}{$\begin{array}{c}0.003(5.78 ; 2) \\
\text { Bonferroni test }(p<0.05) \text { showed a difference between non and current } \\
\text { smokers }\end{array}$} \\
\hline Non-smoker & $7.03(1.86)$ & \\
\hline Past-smoker & $6.37(2.13)$ & \\
\hline Current smoker & $5.33(2.58)$ & \\
\hline
\end{tabular}

Table 3. Correlations between adherence score of $\mathrm{NZ}$ men to a Mediterranean style diet and dependent variables.

\begin{tabular}{|c|c|}
\hline Dependent variables & Pearson's correlation \\
\hline Age & $\mathrm{r}=0.21^{*}$ \\
\hline Income & $\mathrm{r}=0.11$ \\
\hline Opinion on importance of healthy eating & $\mathrm{r}=0.36^{*}$ \\
\hline \multicolumn{2}{|c|}{ Medical conditions } \\
\hline Presence of any condition & $\mathrm{r}=0.05$ \\
\hline High cholesterol & $\mathrm{r}=0.04$ \\
\hline Cardiovascular disease & $\mathrm{r}=0.01$ \\
\hline Hypertension & $\mathrm{r}=0.09$ \\
\hline Cancer & $\mathrm{r}=0.05$ \\
\hline Type 2 diabetes & $\mathrm{r}=0.02$ \\
\hline Arthritis & $\mathrm{r}=0.11$ \\
\hline Lung disorder & $\mathrm{r}=0.05$ \\
\hline Gastro-intestinal disorder & $\mathrm{r}=0.01$ \\
\hline Mental disorder & $\mathrm{r}=-0.07$ \\
\hline Other & $\mathrm{r}=-0.06$ \\
\hline correlation is significant at the 0.01 level. & \\
\hline
\end{tabular}

Participants identified the most important 'major' barrier to consuming a diet which is considered healthy, to be a busy lifestyle (Fig. 1). This selection was followed by the price of healthy foods, willpower, feeling that their diet is already healthy, irregular work hours and not wanting to change their eating habits. It is important to note that $43.6 \%$ of people who indicated that they did not want to change their eating habits also felt that their diet was already healthy.
From Fig. (2) it can be seen that the most common influencers of food choices appear to be other people (wife, family, Nutritionist). This choice is followed in popularity by how the food tasted or their personal preference for certain foods, price, convenience of access and preparation, variety and availability of food options, health reasons, food and nutrient groups (represented by the food of choice) and time available to prepare and consume food.

\section{DISCUSSION}

A modified Prevention with Mediterranean Diet (PREDIMED (Prevención con Dieta Mediterráne) questionnaire [11] was used to determine current adherence of New Zealand men to a Mediterranean style diet and descriptively identified barriers to change.Table 1 shows the characteristics of the sample, indicating that key demographic populations were represented. The mean age of the men sampled was 47 years and 8 months, with a broad age range of 25 to 78 years.

The majority of participants had intermediate adherence to a Mediterranean style diet (Fig. 1), which supports existing literature $[21,22]$. One possible explanation for the low adherence of New Zealand men $(90.8 \%$ of the study participants were scored as low or intermediate adherence) to a Mediterranean diet could be due to recommendations from the Ministry of Health $(\mathrm{MoH})$ that differ from the traditional Mediterranean diet. For example in the 'Eating and Activity Guidelines Statements for New Zealand Adults', produced by the $\mathrm{MoH}$, consumption of red meat up to $500 \mathrm{~g}$ is recommended [23]. This is consistent with WHO recommendations [24], and 


\section{Graph of major barriers to change}

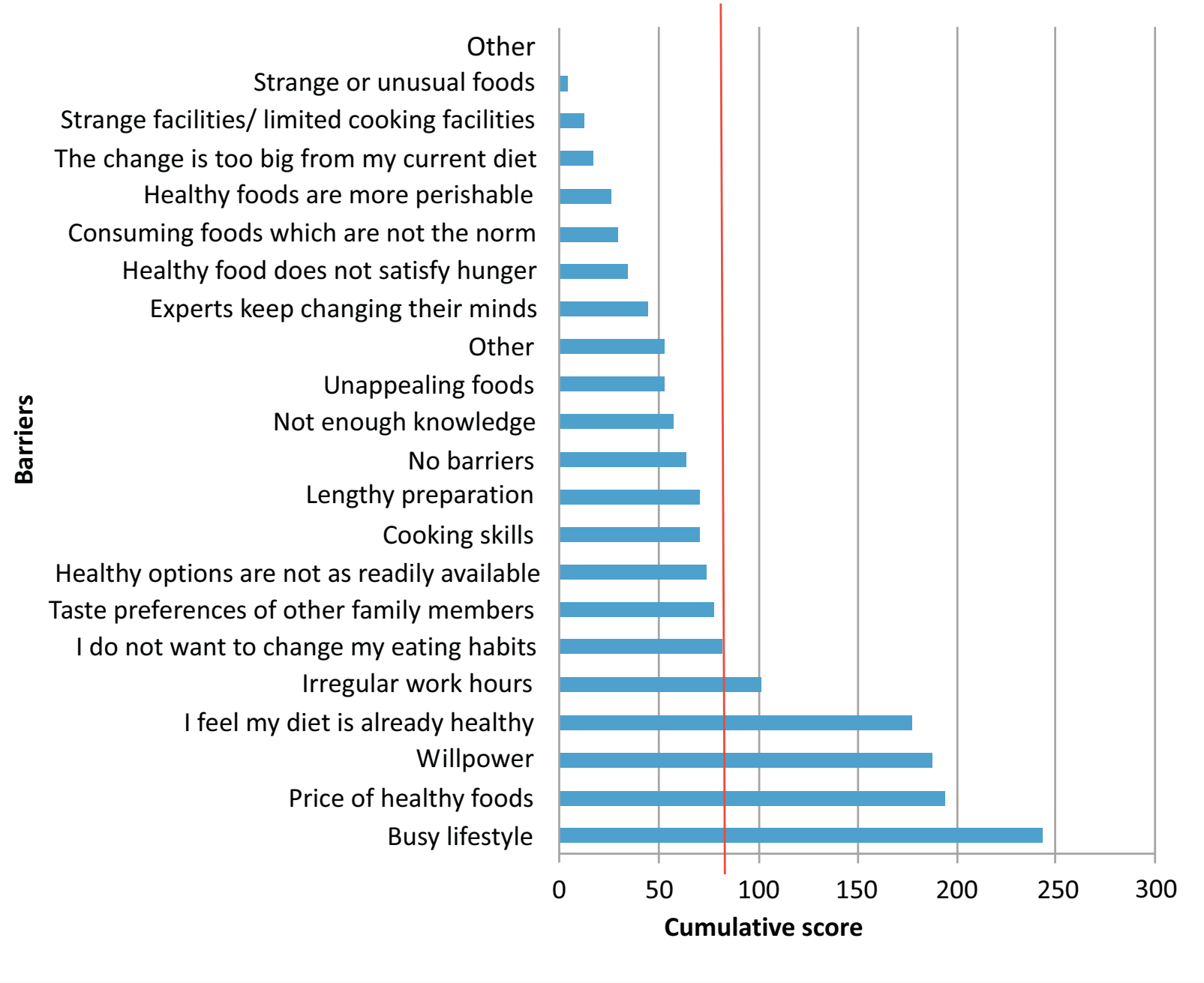

Fig. (1). A bar chart showing major barriers to change plotted against the cumulative barriers to change score. The cumulative score was based on the order in which participants prioritised the list of barriers to change, such that factor 1 contributed 3 points, factor 2 , 2 points and factor 3 , contributed 1 point. The red line represents the inflection point.

these recommendations are partially due to the high levels of iron deficiency in New Zealand [25] that might not exist in Mediterranean countries. Red meat has one of the richest sources of bioavailable iron in the diet and the $\mathrm{MoH}$ has used it to combat anaemia. This recommendation deviates from the Mediterranean style diet, where less than $150 \mathrm{~g}$ is recommended per week by some researchers $[11,26]$. For many New Zealand men an intake of up to $500 \mathrm{~g}$ a week of red meat reflects a decrease in consumption, it is substantially more than is recommended as part of a Mediterranean style diet.

With respect to tobacco use, we found that current smokers had lower adherence than past smokers who had lower adherence when compared to non-smokers (Table 2). This is an unsurprising result supported by existing literature [27]. It has long been proven that current smokers tend to have other detrimental health habits compared to non-smokers [28, 29]. In addition, evidence supports the trend we found that past smokers have lower adherence than non-smokers but greater adherence than current smokers to a Mediterranean style diet [30, 31].

Age was also found to be associated with adherence. The older the participant, the more adherent they were to a Mediterranean style diet (Table 1). Our finding supports previous evidence of higher adherence to a Mediterranean style diet with increasing age [27, 32]. This 'nutrition transition' is discussed by Grosso et al., (2013) and they attribute the changing dietary patterns across the life cycle to changing modern lifestyles, which includes scarce vocational physical activity coupled with improved socioeconomic conditions, leading to an increase in availability of commercial foods [32]. In addition, there may be increasing awareness with increasing age, of the role diet may play in the incidence of noncommunicable diseases, and our increasing vulnerability to these diseases as we age. 


\section{What influences your current food choices?}

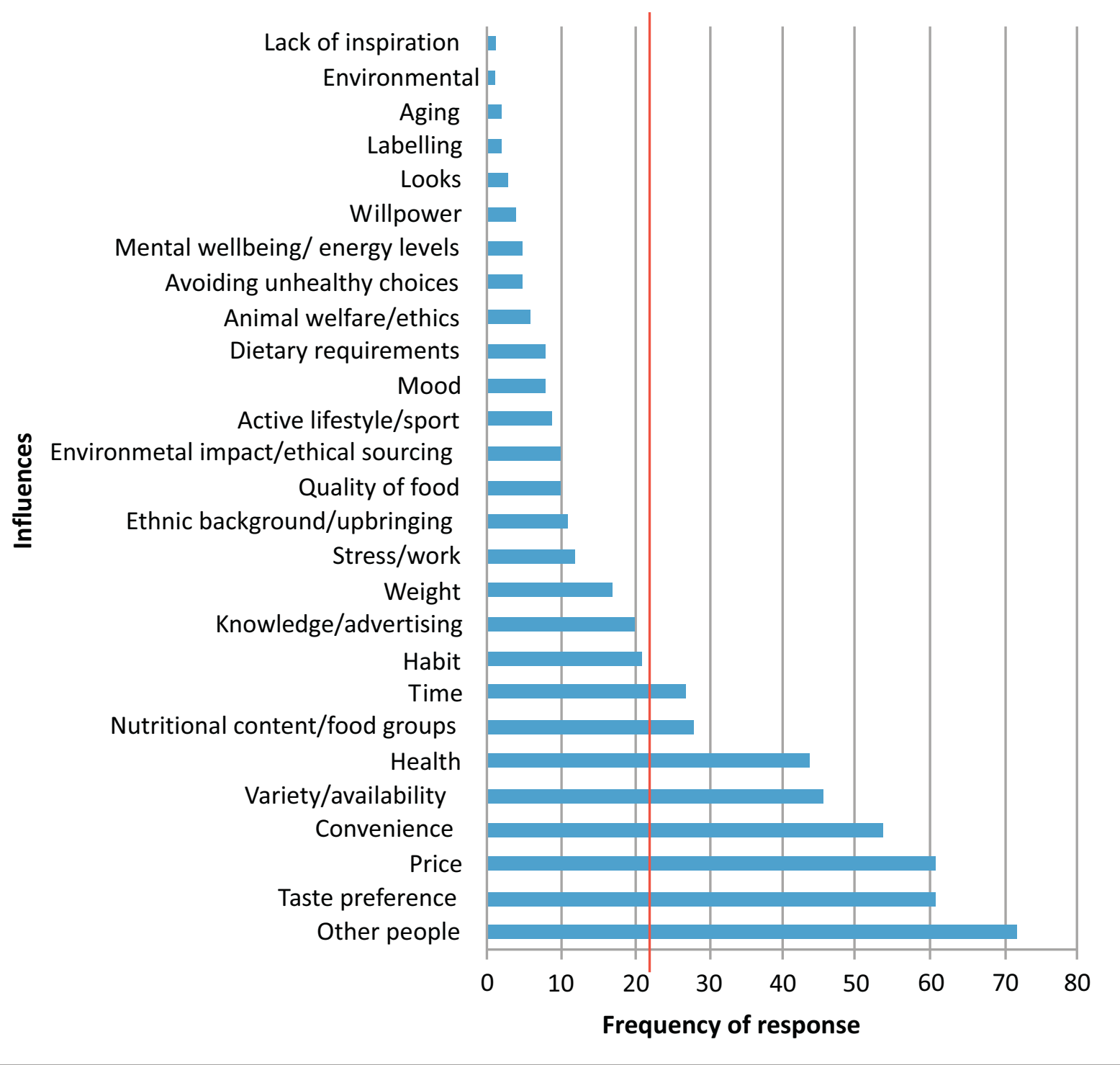

Fig. (2). A bar chart displaying influences on food choices against the number of participants who described the influence.

In addition, the more important the participant considers healthy eating, the higher their adherence (Table 3). This highlights the importance of education and awareness involved in cultivating a healthy diet. A review of the literature performed by Maderuelo-Fernandez et al., (2015) [33] supports this notion. They found that nutritional counselling achieves moderate improvement in dietary habits. However, more research is needed to determine the long-term effect of counselling, including whether or not the changes are maintained and the measured benefit to health outcomes (or otherwise).

Although we found no significant difference in adherence between different education levels (Table 2), our trend of higher education level correlating with higher adherence is supported by existing evidence [21, 27, 32, 34]. Further studies are needed to determine whether this association is due to increased income as a result of higher education and thus grea- ter availability of more costly healthy foods. Grosso et al., (2013) offer another explanation, asserting that the association is due to greater nutritional knowledge by individuals who are more highly educated, which results in greater adherence to the Mediterranean style diet [32]. Certainly, there was a bias towards the receipt of questionnaires from men who had received tertiary education in our study. Although this doesn't invalidate the results, it is a limitation of the study and leads one to question the applicability of the results to the broader NZ population. Had we received a more representative sample of responses, perhaps the mean adherence score would have been lower.

In terms of barriers to consuming a diet which is considered healthy, we identified the main reasons from this study to be a busy lifestyle, price of healthy foods, willpower, feeling 
that the diet is already healthy, irregular work hours and not wanting to change eating habits (Fig. 1). Our results are generally consistent with the existing literature [35 - 37]. Lara et al. [37], whilst investigating the association between the Mediterranean style dietary adherence with barriers to change, also considered other health behaviours, and found that a busy lifestyle was more likely to be a barrier for younger people (average age of 57 years) than older people, and that adherence was associated with age. Our findings were similar and unsurprising given that this age group is usually in full-time employment. In contrast to our own study design, Moore et al. [36] interviewed focus groups (average age of 64 years) in Northern Europe and identified perceived expense, availability of suitable food items and expectation of time commitment as potential barriers to change. Despite the older age, time commitment was considered a potential barrier, and time commitment could be equated to a busy lifestyle as a lack of time is the underlying reason for busy lifestyle being a barrier. It is interesting to note that one of the factors in part three of the questionnaire ("I do not want to change my eating habits") could have either a positive or negative impact on healthy eating habits, depending on what other factors the participant selected in combination with it. That is, if the participant believes they already have a healthy diet then not wanting to change their existing habits is positive for their health outcomes, since they are considered to be at the 'maintenance' stage of the trans-theoretical model for change [38]. However if the participant believes their diet is unhealthy and still does not want to change, this means they are in the 'pre-contempation' stage [38], which puts them behind their counterparts who chose answers such as "busy lifestyle" or "price of healthy foods" ('contemplation' stage) in terms of readiness for dietary change. In fact, we found that $43.6 \%$ of people who did not want to change their eating habits also considered their diets to be already healthy. This has useful implications for future dietary interventions, which can be tailored to each individual stage.

The most common influencers of food choices as determined from our study, appear to be other people (wife, family, Nutritionist), taste preferences, price, convenience of access and preparation, variety and availability of food options, health reasons, the food and nutrient groups making up their meal and time available to consume food Fig. (1). The two most commonly selected influences of food choices may be explai-ned by New Zealand's multicultural society (Table 1). It is common knowledge that there are numerous cultural differences in how food is prepared and by whom. In many cultures, women will traditionally be the ones to prepare food and immigrant families may have a taste preference for their own cultural foods which vary from a Mediterranean style diet.
Additionally, a culinary 'acculturation' may exist in New Zealand, leading to a number of health outcomes, including unhealthy weight gain when the New Zealand dietary habits promote more unhealthy habits than the heritage culture [39]. This acculturation effect could be an interesting research point for a future study.

However, a point to consider is the wording of the questions. The wording of the question on influences asks "What influences...", and this use of "what" may have led the respondent to respond with something rather than someone. In addition to this limitation, we were only able to recruit $77 \%$ of the required sample number.

\section{CONCLUSION}

We conclude that a large proportion of the study participants experience a low or intermediate adherence to a Mediterranean style diet. Two of the most important barriers to changing diets were a busy lifestyle and the price of healthy foods. It has long been proven that a Mediterranean style diet is associated with better health outcomes, and we now know to focus initiatives towards negating these two most important barriers.

It is difficult to change behaviour without a corresponding change in environment and policy. A British study found that a major barrier to changing diets is a non-conducive culture to change [35]. Hence this study is important in identifying how NZ men consume food and what they consider as their barriers to change. The study findings indicate that we can better direct policy to aid changes in behaviour and integrate, at least in part, more acceptance of the Mediterranean style diet by the NZ public. Clearly, a community and/or family approach may be more beneficial than targeting interventions at an individual.

\section{LIST OF ABBREVIATIONS}

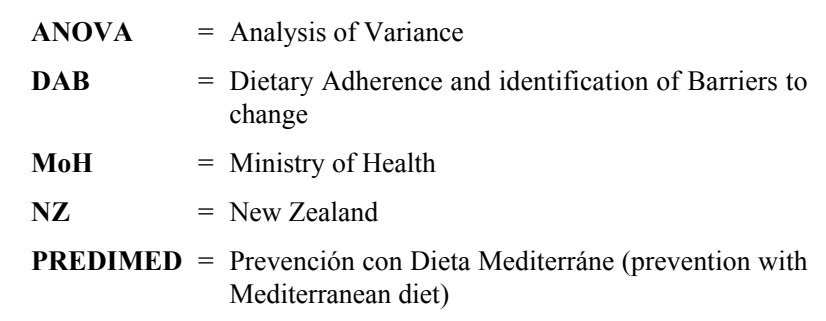

\section{ETHICS APPROVAL AND CONSENT TO PARTICI- PATE}

The study was implemented and procedures followed in accordance with the ethical standards of the University of Auckland Human Participants Ethics Committee (Ethics \# 013884).

\section{HUMAN AND ANIMAL RIGHTS}

No animals/humans were used for studies that are the basis of this research. 


\section{CONSENT FOR PUBLICATION}

Not applicable.

\section{AVAILABILITY OF DATA AND MATERIALS}

The data supporting the findings of the article are available in the Figshare repository at https://figshare.com, reference number 10.6084/m9.figshare.8091248.

\section{FUNDING}

The study was supported by The University of Auckland, School of Medicine Foundation.

\section{CONFLICT OF INTEREST}

The authors declare no conflict of interest, financial or otherwise

\section{ACKNOWLEDGEMENTS}

Funding to IPJ and WY from The University of Auckland, School of Medicine Foundation, is acknowledged. KSB and MAH designed the study. IPJ designed drafts of the questionnaire, obtained feedback from KSB and MAH, and finalised the questionnaire. KB and WY administered the questionnaire. WY analysed the data with guidance from MAH. KSB wrote the manuscript. WY prepared the tables and figures.

\section{SUPPLEMENTARY MATERIAL}

Supplementary material is available on the publishers website along with the published article.

APPENDIX

\section{Dietary Questionnaire}

Thank-you for agreeing to take part and complete this short questionnaire.

This is completely anonymous and the results will be used to gain an insight into the current adherence of men in New Zealand to a Mediterranean style diet.

Part one of the questionnaire includes 14 questions. 11 of these will involve estimating your average intake of food groups on a daily or weekly basis and the remaining 3 questions will involve selecting either YES or NO

$$
\text { or VEGETARIAN }
$$

For part one, images have been included in the questionnaire to give you an idea of what a serving size looks like for that particular food.

Part two of the questionnaire involves 7 questions relating to demographics and will enable us to identify trends in different

$$
\text { populations. }
$$

Part three of this questionnaire contains 3 questions which relate to your thoughts about healthy eating and current eating habits.

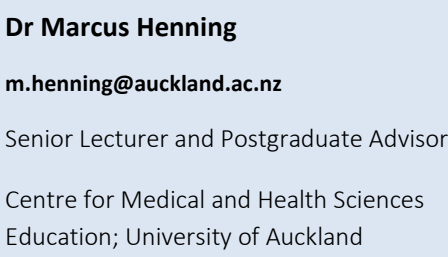




\section{Part One}

The following five questions will ask you about your average intake of food groups on a DAILY basis.

\begin{tabular}{|c|c|}
\hline $\begin{array}{l}\text { On average, how many servings of fruit do you } \\
\text { consume in one day? }\end{array}$ & $\begin{array}{l}\text { One serving will } \\
\text { fit in the palm } \\
\text { of your hand }\end{array}$ \\
\hline $\begin{array}{l}\text { On average, how many servings of vegetables } \\
\text { do you consume in one day? }\end{array}$ & $\begin{array}{l}\text { One serving will } \\
\text { fit in the palm } \\
\text { of your hand }\end{array}$ \\
\hline $\begin{array}{l}\text { On average, how many servings of sweetened } \\
\text { or fizzy beverages do you consume per day? } \\
\text { (Such as cola, Fanta or lemonade) }\end{array}$ & $\begin{array}{l}\text { One serving is } 100 \mathrm{ml} \\
\text { this is just under half of } \\
\text { a standard mug }\end{array}$ \\
\hline $\begin{array}{l}\text { On average, how many servings of butter, } \\
\text { margarine or cream do you consume per day? }\end{array}$ & $\begin{array}{l}\text { One serving is } 12 \mathrm{~g} \text {, } \\
\text { almost a full } \\
\text { tablespoon }\end{array}$ \\
\hline $\begin{array}{l}\text { On average, how many servings of green tea } \\
\text { do you drink per day? }\end{array}$ & $\begin{array}{l}\text { One serving is } 100 \mathrm{ml} \\
\text { this is just under half of } \\
\text { a standard mug }\end{array}$ \\
\hline
\end{tabular}

The following three questions will ask you about your current food habits, please select YES or NO or VEGETARIAN

\begin{tabular}{|c|c|c|c|}
\hline $\begin{array}{l}\text { Do you preferentially choose wholegrain cereals } \\
\text { over a more processed alternative? (Such as } \\
\text { wholemeal brown bread vs white bread) }\end{array}$ & $\begin{array}{l}\text { YES } \\
\square\end{array}$ & NO & \\
\hline $\begin{array}{l}\text { Do you use olive oil for cooking or as an addition } \\
\text { to meals? }\end{array}$ & $\begin{array}{l}\text { YES } \\
\square\end{array}$ & No & \\
\hline $\begin{array}{l}\text { Do you preferentially choose chicken or turkey } \\
\text { over red meats such as steak, mince or pork? }\end{array}$ & $\begin{array}{l}\text { YES } \\
\square\end{array}$ & $\begin{array}{l}\text { NO } \\
\square\end{array}$ & $\begin{array}{l}\text { VEGETARIAN } \\
\square\end{array}$ \\
\hline
\end{tabular}

DAB Feasibility Study: Dietary Adherence and Barriers to Healthy Eating - Version 2 Ethics Ref: 013884 
The following six questions will ask you about your average intake of food groups on a WEEKLY basis

\begin{tabular}{|c|c|}
\hline $\begin{array}{c}\text { On average, how many servings of } \\
\text { red meat do you consume in a } \\
\text { week? (beef steak, mince, sausage, } \\
\text { pork) }\end{array}$ & $\begin{array}{l}\text { A full serving is } \\
100-150 \mathrm{~g} \text { this is } \\
\text { about the same } \\
\text { size as a standard } \\
\text { CD }\end{array}$ \\
\hline $\begin{array}{c}\text { On average, how many glasses of } \\
\text { wine do you consume per week? } \\
\text { (does not include any other alcoholic } \\
\text { beverage) }\end{array}$ & $\begin{array}{l}\text { One glass of wine is } \\
100 \mathrm{ml} \text {. This fills up to } \\
\text { the widest part of a } \\
\text { standard wine glass }\end{array}$ \\
\hline $\begin{array}{l}\text { On average, how many servings of } \\
\text { fish or shellfish do you consume per } \\
\text { week? }\end{array}$ & $\begin{array}{l}\text { A full serving is } \\
100-150 \mathrm{~g} \text { this is } \\
\text { about the same } \\
\text { size as a standard } \\
\text { CD or } 4-5 \text { units of } \\
\text { shellfish }\end{array}$ \\
\hline $\begin{array}{l}\text { On average, how many servings of } \\
\text { peas, beans, bean sprouts, peanuts } \\
\text { or lentils do you consume per week? }\end{array}$ & $\begin{array}{l}\text { serving is } 150 \mathrm{~g} \text {, or } \\
\text { half a cup. }\end{array}$ \\
\hline $\begin{array}{c}\text { On average, how many times per } \\
\text { week do you consume sweets or } \\
\text { pastries, such as cakes, cookies or } \\
\text { biscuits? }\end{array}$ & \\
\hline $\begin{array}{l}\text { On average, how many servings of } \\
\text { nuts do you consume per week? } \\
\text { (almonds, hazelnuts, brazil nuts, } \\
\text { excludes peanuts) }\end{array}$ & $\begin{array}{l}\text { A serving of nuts is } \\
30 \mathrm{~g} \text {, this is } 20-25 \\
\text { almonds or } 6-8 \\
\text { brazil nuts }\end{array}$ \\
\hline
\end{tabular}

DAB Feasibility Study: Dietary Adherence and Barriers to Healthy Eating - Version 2 


\section{Part Two}

\section{Please state your age in years.}

\section{Please circle which ethnic group/s you belong to?}

New Zealand European

Maori

Samoan

Cook Island Maori
Tongan

Niuean

Chinese

Indian

\section{Please estimate your average annual income.}

\section{Please circle your highest level of education.}

1. School Certificate

4. Postgraduate Study
2. Trade certificate

3. Undergraduate Degree

\section{What is your smoking status?}

Past-Smoker

Current Smoker

Non-Smoker

Please circle any of the following conditions that you have been clinically diagnosed with.
Cancer
Type 2 Diabetes
Cardiovascular Disease

High Cholesterol

Hypertension

Other chronic illness

Not Applicable 
Please select three of the following factors you believe are MAJOR barriers towards consuming a diet which is considered healthy. Rank these factors from 1 to 3, with

\section{1 being the most significant barrier:}

Irregular work hours

Busy lifestyle

Willpower

I do not want to change my eating habits

The change is too big from my current diet

Cooking skills

Healthy foods are more perishable

Lengthy preparation

Storage facilities/ limited cooking facilities

Price of healthy foods

Unappealing foods

Strange or unusual foods

Consuming foods which are not the 'norm' in your workplace/home life

Taste preferences of other family members

Not enough knowledge

Experts keep changing their minds about healthy foods

Healthy options are not as readily available as unhealthy

Healthy food does not satisfy hunger

I feel my diet is already healthy

Other (please specify)

No barriers

DAB Feasibility Study: Dietary Adherence and Barriers to Healthy Eating - Version 2

Ethics Ref: 013884 


\section{How important is healthy eating to you?}

Not Important

1

2

4

Very Important

56

Why did you choose this answer?

What influences your current food choices?

DAB Feasibility Study: Dietary Adherence and Barriers to Healthy Eating - Version 2

Ethics Ref: 013884 


\section{REFERENCES}

[1] Grammaticos PC, Diamantis A. Useful known and unknown views of the father of modern medicine, Hippocrates and his teacher Democritus. Hell J Nucl Med 2008; 11(1): 2-4 [PMID: 18392218]

[2] Keys A. A practical, palatable and prudent way of eating. J Med Assoc Ga 1970; 59(9): 355-9. [PMID: 5452772]

[3] Schwingshackl L, Chaimani A, Hoffmann G, Schwedhelm C, Boeing H. A network meta-analysis on the comparative efficacy of different dietary approaches on glycaemic control in patients with type 2 diabetes mellitus. Eur J Epidemiol 2018; 33(2): 157-70. [http://dx.doi.org/10.1007/s10654-017-0352-x] [PMID: 29302846]

[4] Revelas A, Arvanitakis D. The Mediterranean diet: A short review of the health benefits: Forum. S Afr Fam Pract 2011; 53: 459-61. [http://dx.doi.org/10.1080/20786204.2011.10874134]

[5] Sofi F, Abbate R, Gensini GF, Casini A. Accruing evidence on benefits of adherence to the Mediterranean diet on health: An updated systematic review and meta-analysis. Am J Clin Nutr 2010; 92(5): 1189-96.

[http://dx.doi.org/10.3945/ajcn.2010.29673] [PMID: 20810976]

[6] Casas R, Sacanella E, Urpí-Sardà M, et al. The effects of the mediterranean diet on biomarkers of vascular wall inflammation and plaque vulnerability in subjects with high risk for cardiovascular disease. A randomized trial. PLoS One 2014; 9(6): e100084. [http://dx.doi.org/10.1371/journal.pone.0100084] [PMID: 24925270]

[7] Dai J, Jones DP, Goldberg J, et al. Association between adherence to the Mediterranean diet and oxidative stress. Am J Clin Nutr 2008; 88(5): 1364-70.

[PMID: 18996873]

[8] Sofi F, Cesari F, Abbate R, Gensini GF, Casini A. Adherence to Mediterranean diet and health status: Meta-analysis. BMJ 2008; 337 : a1344.

[http://dx.doi.org/10.1136/bmj.a1344] [PMID: 18786971]

[9] Martinez-Gonzalez MA, Bes-Rastrollo M. Dietary patterns, Mediterranean diet, and cardiovascular disease. Curr Opin Lipidol 2014; 25(1): 20-6.

[http://dx.doi.org/10.1097/MOL.0000000000000044] [PMID: 2437 0845]

[10] Singh B, Parsaik AK, Mielke MM, et al. Association of mediterranean diet with mild cognitive impairment and Alzheimer's disease: A systematic review and meta-analysis. J Alzheimers Dis 2014; 39(2): 271-82.

[http://dx.doi.org/10.3233/JAD-130830] [PMID: 24164735]

[11] Martínez-González MA, García-Arellano A, Toledo E, et al. A 14item Mediterranean diet assessment tool and obesity indexes among high-risk subjects: The PREDIMED trial. PLoS One 2012; 7(8): e43134.

[http://dx.doi.org/10.1371/journal.pone.0043134] [PMID: 22905215]

[12] Itsiopoulos C, Hodge A, Kaimakamis M. Can the Mediterranean diet prevent prostate cancer? Mol Nutr Food Res 2009; 53(2): 227-39. [http://dx.doi.org/10.1002/mnfr.200800207] [PMID: 19051189]

[13] Ministry_of_Health. Selected cancers 2014, 2015, 2016 (New Zealand Cancer Registry) 2018. https://www.health.govt.nz/publication/ selected-cancers-2014-2015-2016

[14] Ministry_of_Health. A. Services; Mortality: Historical Summary 1948-2015 2018.

[15] Bishop KS, Erdrich S, Karunasinghe N, et al. An investigation into the association between DNA damage and dietary fatty acid in men with prostate cancer. Nutrients 2015; 7(1): 405-22. [http://dx.doi.org/10.3390/nu7010405] [PMID: 25580814]

[16] Stats NZ. Census 2017.https://www.stats.govt.nz/topics/census

[17] Martínez-González MA, Fernández-Jarne E, Serrano-Martínez M, Marti A, Martinez JA, Martín-Moreno JM. Mediterranean diet and reduction in the risk of a first acute myocardial infarction: An operational healthy dietary score. Eur J Nutr 2002; 41(4): 153-60. [http://dx.doi.org/10.1007/s00394-002-0370-6] [PMID: 12242583]

[18] Schröder H, Fitó M, Estruch R, et al. A short screener is valid for assessing Mediterranean diet adherence among older Spanish men and women. J Nutr 2011; 141(6): 1140-5.

[http://dx.doi.org/10.3945/jn.110.135566] [PMID: 21508208]

[19] Martínez-González MA, Fernández-Jarne E, Serrano-Martínez M, Wright M, Gomez-Gracia E. Development of a short dietary intake questionnaire for the quantitative estimation of adherence to a cardioprotective Mediterranean diet. Eur J Clin Nutr 2004; 58(11): 1550-2. [http://dx.doi.org/10.1038/sj.ejcn.1602004] [PMID: 15162136]

[20] López-Azpiazu I, Martínez-González MA, Kearney J, Gibney M, Martínez JA. Perceived barriers of, and benefits to, healthy eating reported by a Spanish national sample. Public Health Nutr 1999; 2(2): 209-15.

[http://dx.doi.org/10.1017/S1368980099000269] [PMID: 10447249]

[21] Grosso G, Galvano F. Mediterranean diet adherence in children and adolescents in southern European countries. NFS Journal 2016; 3: 13-9.

[http://dx.doi.org/10.1016/j.nfs.2016.02.004]

[22] Crichton GE, Bryan J, Hodgson JM, Murphy KJ. Mediterranean diet adherence and self-reported psychological functioning in an Australian sample. Appetite 2013; 70: 53-9.

[http://dx.doi.org/10.1016/j.appet.2013.06.088] [PMID: 23831151]

[23] Ministry_of_Health. Eating and Activity Guidelines for New Zealand Adults.

2015.https://www.health.govt.nz/system/files/documents/publications/ eating-activity-guidelines-for-new-zealand-adults-oct15_0.pdf

[24] World-Cancer-Research-Fund/American-Institute-for-CancerResearch. Continuous Update Project Expert Report 2018 Recommendations and public health and policy implications 2018.

[25] Johnson AD. The role of red meat in a healthy New Zealand diet report

2015.http://www.beeflambnz.co.nz/resources/Role_of_Red_Meat_Rep ort.pdf

[26] Wade AT, Davis CR, Dyer KA, et al. Including pork in the Mediterranean diet for an Australian population: Protocol for a randomised controlled trial assessing cardiovascular risk and cognitive function. Nutr J 2017; 16(1): 84

[http://dx.doi.org/10.1186/s12937-017-0306-x] [PMID: 29273039]

[27] Hu EA, Toledo E, Diez-Espino J, et al. Lifestyles and risk factors associated with adherence to the Mediterranean diet: A baseline assessment of the PREDIMED trial. PLoS One 2013; 8(4): e60166. [http://dx.doi.org/10.1371/journal.pone.0060166] [PMID: 23637743]

[28] Lloveras G, Ribas Barba L, Ramon JM, Serra Majem L, Román Viñas B. Food consumption and nutrient intake in relation to smoking. Med Clin (Barc) 2001; 116(4): 129-32. [PMID: 11222158]

[29] Dallongeville J, Marécaux N, Fruchart JC, Amouyel P. Cigarette smoking is associated with unhealthy patterns of nutrient intake: A meta-analysis. J Nutr 1998; 128(9): 1450-7.

[http://dx.doi.org/10.1093/jn/128.9.1450] [PMID: 9732304]

[30] Morabia A, Curtin F, Bernstein MS. Effects of smoking and smoking cessation on dietary habits of a Swiss Urban population. Eur J Clin Nutr 1999; 53(3): 239-43.

[http://dx.doi.org/10.1038/sj.ejen.1600710] [PMID: 10201807]

[31] Morabia A, Wynder EL. Dietary habits of smokers, people who never smoked, and exsmokers. Am J Clin Nutr 1990; 52(5): 933-7.

[http://dx.doi.org/10.1093/ajen/52.5.933] [PMID: 2239771]

[32] Grosso G, Marventano S, Buscemi S, et al. Factors associated with adherence to the Mediterranean diet among adolescents living in Sicily, Southern Italy. Nutrients 2013; 5(12): 4908-23. [http://dx.doi.org/10.3390/nu5124908] [PMID: 24304608]

[33] Maderuelo-Fernandez JA, Recio-Rodríguez JI, Patino-Alonso MC, et al. Effectiveness of interventions applicable to primary health care settings to promote Mediterranean diet or healthy eating adherence in adults: A systematic review. Prev Med 2015; 76(Suppl.): S39-55. [http://dx.doi.org/10.1016/j.ypmed.2014.12.011] [PMID: 25524613]

[34] Fauquet J, Sofi F, López-Guimerà G, et al. Mediterranean diet adherence among Catalonian adolescents: Socio-economic and lifestyle factors. Nutr Hosp 2016; 33(6): 1283-90. [http://dx.doi.org/10.20960/nh.772] [PMID: 28000454]

[35] Middleton G, Keegan R, Smith MF, Alkhatib A, Klonizakis M. Brief report: Implementing a mediterranean diet intervention into a RCT: Lessons learned from a Non-Mediterranean based country. J Nutr Health Aging 2015; 19(10): 1019-22. [http://dx.doi.org/10.1007/s12603-015-0663-0] [PMID: 26624214]

[36] Moore SE, McEvoy CT, Prior L, et al. Barriers to adopting a Mediterranean diet in Northern European adults at high risk of developing cardiovascular disease. J Hum Nutr Diet 2017. [PMID: 29159932]

[37] Lara J, McCrum LA, Mathers JC. Association of Mediterranean diet and other health behaviours with barriers to healthy eating and perceived health among British adults of retirement age. Maturitas 2014; 79(3): 292-8.

[http://dx.doi.org/10.1016/j.maturitas.2014.07.003] [PMID: 25096829]

[38] Greene GW, Rossi SR, Rossi JS, Velicer WF, Fava JL, Prochaska JO. 
Dietary applications of the stages of change model. J Am Diet Assoc 1999; 99(6): 673-8.

[http://dx.doi.org/10.1016/S0002-8223(99)00164-9] [PMID: 1036 1528]
[39] Delavari M, Sønderlund AL, Swinburn B, Mellor D, Renzaho A. Acculturation and obesity among migrant populations in high income countries--a systematic review. BMC Public Health 2013; 13: 458 [http://dx.doi.org/10.1186/1471-2458-13-458] [PMID: 23663279]

\section{(C) 2019 Bishop et al.}

This is an open access article distributed under the terms of the Creative Commons Attribution 4.0 International Public License (CC-BY 4.0), a copy of which is available at: https://creativecommons.org/licenses/by/4.0/legalcode. This license permits unrestricted use, distribution, and reproduction in any medium, provided the original author and source are credited. 